\title{
Erratum
}

\section{Pollen movement in a Malus sylvestris population and conclusions for conservation measures - ERRATUM}

Stefanie Reim, Anke Proft, Simone Heinz, Frank Lochschmidt, Monika Höfer, Ute Tröber and Heino Wolf

(First published online 29 September 2015)

doi:10.1017/S1479262115000301. Published online by Cambridge University Press 14 August 2015.

The right address of Monika $\mathrm{Höfer}^{3}$ is:

${ }^{3}$ Julius Kühn-Institute, Institute for Breeding Research on Fruit Crops, Pillnitzer Platz 3a, D-01326 Dresden, Germany

\section{Reference}

Reim S, Proft A, Heinz S, Lochschmidt F, Höfer M, Tröber U and Wolf H (2015) Pollen movement in a Malus sylvestris population and conclusions for conservation measures. Plant Genetic Resources: Characterization and Utilization. Published online by Cambridge University Press 14 August 2015, doi:10.1017/S1479262115000301. 